\title{
Structural modification of tantalum crystal induced by nitrogen ion implantation
}

\author{
A H RAMEZANI*, M R HANTEHZADEH, M GHORANNEVISS and E DARABI \\ Plasma Physics Research Center, Science and Research Branch, Islamic Azad University, Tehran 16315-835, Iran
}

MS received 1 September 2015; accepted 4 January 2016

\begin{abstract}
This paper investigates the effect of nitrogen ion implantation on tantalum surface structure. In this experiment, nitrogen ions which had an energy of $30 \mathrm{keV}$ and doses of $1 \times 10^{17}$ to $10 \times 10^{17}$ ions $\mathrm{cm}^{-2}$ were used. X-ray diffraction analysis (XRD) was applied for both the metallic Ta substrate and the study of new structures that have been created through the nitrogen ion implantation. Atomic force microscopy (AFM) was also used to check the roughness variations prior to and also after the implantation phase. The experimental results show the formation of hexagonal tantalum nitride $\left(\mathrm{TaN}_{0.43}\right)$ in addition to the fact that by increasing the ion dose, the nitrogen atoms occupy more interstitial spaces in the target crystal. The nitride phase also seen for $3 \times 10^{17}$ and $5 \times 10^{17}$ ions $\mathrm{cm}^{-2}$, while it disappeared for higher dose of $7 \times 10^{17}$ and $1 \times 10^{18}$ ions $\mathrm{cm}^{-2}$. The FWHM of the dominant peak of tantalum nitride suggest the growth of the crystallite's size, which is in agreement with the AFM results of the grains.
\end{abstract}

Keywords. Ion implantation; nitrogen; tantalum; XRD; AFM.

\section{Introduction}

The effect of nitrogen ion implantation on the structural, mechanical, even biological and tribological properties of different materials has been studied intensively [1-3]. Tantalum nitride is well known for its applications in microelectronics. It can be used in hybrid integrated circuit technology and for other special applications. The grade of surface modification by nitrogen ion implantation depends on the ion energy, current density, irradiation time and the substrate temperature. Tantalum and tantalum nitride have a wide industrial range of applications. For example, tantalum has obtained plenty of attention as a new metallic biomaterial due to its excellent corrosion resistance $[4,5]$. There are various methods such as molecular beam epitaxy (MBE), RF reactive magnetron sputtering and laser ablation to produce tantalum nitride $[6,7]$. Nevertheless, owing to difficulty in tantalum nitride formation by ion implantation, there have been few reports concerning nitride formation on Ta using ion implantation [8-15]. Tantalum nitride can also be used as an excellent diffusion barrier in complementary metal oxide semiconductor devices [16] and has a potential application as a hard-coating material [17]. Ion implantation can be effectively used to form such hard coatings. Several reports have appeared in the last few years about the preparation and characterization of tantalum nitride thin films [1,18-24]. Tantalum nitride has recently been attracted considerable attention due to its special properties such as good adhesion to dielectrics and high thermal stability [25-27], stable electrical

\footnotetext{
*Author for correspondence (ramezani.1972@gmail.com)
}

resistance [28], chemical inertness and high mechanical hardness $[29,30]$.

In this study, the results of nitrogen ion implantation into tantalum samples are discussed. The structural, compositional changes of modified surfaces as a function of ion dose are studied as well. The aim of this work is to find the optimum condition for effective improvement of the surface properties.

\section{Materials and experimental techniques}

The process of ion bombardment was performed on samples of tantalum with sizes of $1 \mathrm{~cm} \times 1 \mathrm{~cm}$ and $0.58 \mathrm{~mm}$ thickness by the ion implantation facility of Plasma Physics Research Center (PPRC) at Science and Research Branch. The ion bombardment procedure was performed by nitrogen ions $(99.999 \%)$ with the energy of $30 \mathrm{keV}$ and doses of $1 \times$ $10^{17}$ to $10 \times 10^{17}$ ions $\mathrm{cm}^{-2}$ at ambient temperature, while the angle between the implanted ions and surface of samples was $90^{\circ}$. Prior to ion implantation, the sample surfaces were polished in a manner that resulted in a glossy finish using diamond paste. All samples were then ultrasonically cleaned in alcohol and acetone. The extracted ions (without mass selection) were accelerated to the maximum energy of 30 $\mathrm{keV}$. Ion beam energy and current densities were kept fixed for all the samples. The samples were implanted at doses of $1 \times 10^{17}$ to $10 \times 10^{17}$ ions $\mathrm{cm}^{-2}$. It is expected that the ion beam cross section uniformly covers all the sample area. The implantation parameters have been listed in table 1. Prior to beginning of the ion implantation, the samples were at room temperature. However, this temperatures is altered during the 
Table 1. Ion implantation data.

\begin{tabular}{lccccc}
\hline $\begin{array}{l}\text { Sample } \\
(\#)\end{array}$ & $\begin{array}{c}\text { Energy } \\
(\mathrm{keV})\end{array}$ & $\begin{array}{c}\text { Ion current } \\
\left(\mu \mathrm{A} \mathrm{cm} \mathrm{cm}^{-2}\right)\end{array}$ & $\begin{array}{c}\text { Dose (ions } \\
\left.\mathrm{cm}^{-2}\right)\end{array}$ & $\begin{array}{c}\text { Time } \\
(\mathrm{s})\end{array}$ & $\begin{array}{c}\text { Temperature } \\
\left({ }^{\circ} \mathrm{C}\right)\end{array}$ \\
\hline 1 & 30 & 40 & $1 \times 10^{17}$ & 360 & 100 \\
2 & 30 & 40 & $3 \times 10^{17}$ & 470 & 100 \\
3 & 30 & 40 & $5 \times 10^{17}$ & 700 & 100 \\
4 & 30 & 40 & $7 \times 10^{17}$ & 1120 & 100 \\
5 & 30 & 40 & $10 \times 10^{17}$ & 1600 & 100 \\
\hline
\end{tabular}

implantation due to the heat transfer which is from the ion bombardment to the samples as shown in table 1 .

Structural characteristics and composition of samples were analysed using various methods. The microstructure of the samples before and after ion implantation was characterized by X-ray diffraction (XRD) analysis using the STOE model STADI MP system with Cuk $\alpha$ radiation (wavelength $=1.5405 \AA$ ), tungsten filament at $40 \mathrm{kV}, 40 \mathrm{~mA}$ and step size of $0.04^{\circ}$. The implantation-induced modification of surface roughness was studied employing an atomic force microscopy (AFM). The facility was an AFM (SPM Auto Probe CP, Park Scientific Instruments, USA) in contact mode with a low stress tantalum nitride tip of less than $200 \AA$ Aradii. AFM analysis in contact mode, as well as the scanning area of $1 \mu \mathrm{m}^{2}$ was used to study surface topography and roughness. Scanning electron microscopy (SEM), LEO 440I system is utilized to study the surface texture and modification of samples after ion implantation.

\section{Results and discussion}

\subsection{Crystallographic structure}

According to SRIM simulation, at $30 \mathrm{keV}$, the maximum penetration depth of nitrogen ions in tantalum is about $523 \AA$ [16]. Moreover, at $30 \mathrm{keV}$, the electronic stopping power $\left(26.7 \mathrm{eV}^{-1}\right)$ is higher than nuclear stopping $(14.2 \mathrm{eV}$ $\AA^{-1}$ ) by a factor close to 2 . This means that the stopping of the nitrogen ions in tantalum substrate is dominantly due to the interaction with the tantalum electrons rather than tantalum atoms. Figure 1 shows the result of an XRD analysis of unplanted sample. XRD results are listed in table 2 for unimplanted sample, four lines of $\alpha$-Ta as $\mathrm{Ta}(110), \mathrm{Ta}(200)$, $\mathrm{Ta}(211)$ and $\mathrm{Ta}(220)$ are seen, respectively (PDF card \#40788). XRD results with phase identification are listed in tables 3 and 4 for samples 2 and 3. Although at the implantation dose of $1 \times 10^{17}$ ions $\mathrm{cm}^{-2}$ new crystalline phases cannot be observed, significant shifts of Ta lines towards lower $2 \theta$ angles are seen. This shift is also observed at higher implantation doses. In addition, an increase in this shift is observed as the implantation dose is further increased. By increasing the ion dose in the range of ( 3 to 5$) \times 10^{17}$ ions $\mathrm{cm}^{-2}$, formation of hexagonal $\mathrm{TaN}_{0.43}$ is confirmed by XRD analysis (PDF cards \#71-0265). Figure 2 shows the results of XRD analysis of ion-implanted samples. At higher doses

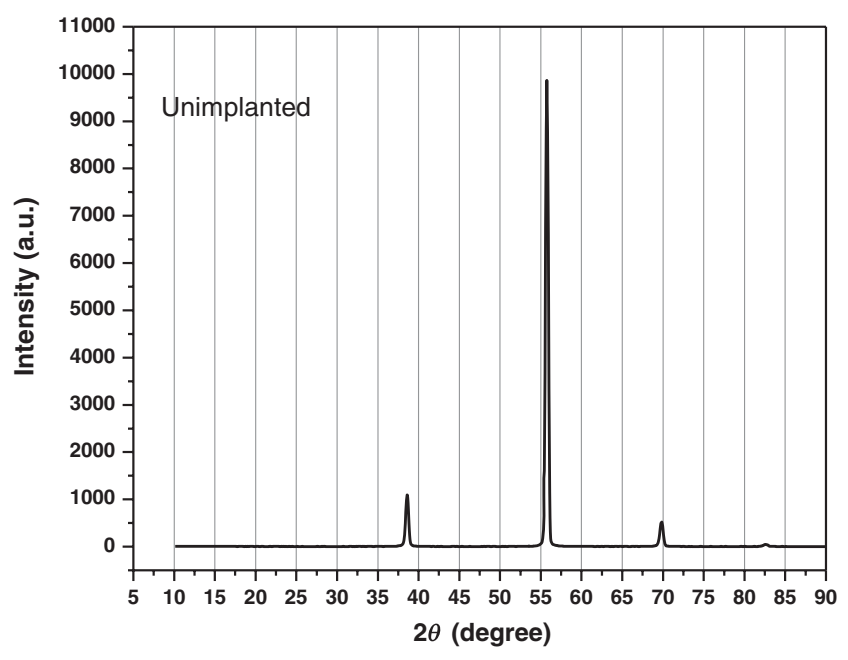

Figure 1. X-ray diffraction spectrum of unimplanted tantalum.

Table 2. Identification of XRD peaks in figure 1 (unimplanted sample).

\begin{tabular}{lcccccc}
\hline & $2 \theta$ & & & \multicolumn{3}{c}{ Intensity } \\
Peak & (degree) & $d$ (observed) & $d$ (standard) & $h k l$ & $(\%)$ & Phase \\
\hline A & 38.66 & 2.239 & 2.326 & 110 & 10 & bcc Ta \\
B & 55.76 & 1.648 & 1.646 & 200 & 100 & bcc Ta \\
C & 69.82 & 1.347 & 1.345 & 211 & 5.25 & bcc Ta \\
D & 82.50 & 1.168 & 1.168 & 200 & 0.43 & bcc Ta \\
\hline
\end{tabular}

of $(3-5) \times 10^{17}$ ions $\mathrm{cm}^{-2}$, many additional peaks were observed. Four intense peaks of bcc Tantalum and G, L and $\mathrm{O}$ for dose of $3 \times 10^{17}$ ions $\mathrm{cm}^{-2}$ and peaks $\mathrm{Q}$ and $\mathrm{S}$ for dose of $5 \times 10^{17}$ ions cm$~^{-2}$ are due to fcc $\mathrm{TaN}_{0.43}$ and $\mathrm{Ta}_{3} \mathrm{~N}_{5}$ phases, as identified in tables 3 and 4 . The above results are compared with the results of previous reports which observed the formation of fcc and hcp Ta-N [30-33].

The significance of small shifts of Ta lines towards lower $2 \theta$ angles observed, indicates that the nitrogen atoms are introduced into spaces between the lattice positions and increase the distance between atomic layers. At higher doses of $7 \times$ $10^{17}$ and $1 \times 10^{18}$ ions $\mathrm{cm}^{-2}$, the peaks of tantalum nitride disappear and only the substrate peaks can be seen. At ion doses, when the depth profile is sputter-limited, nitrogen ions are bombarded on a previously-formed tantalum nitride. When the dose is increased, a large number of interstitial nitrogen atoms will produce strain in the lattice itself, which causes the increased lattice spacing and synthesis of tantalum nitride $\left(\mathrm{TaN}_{0.43}\right)$. It can be concluded that by the ion dose growth, the lattice spaces are increased and more interstitial spaces in the target crystal are occupied by nitrogen atoms. In addition, tantalum nitride is formed at moderate doses ( 3 to $5 \times 10^{17}$ ions $\mathrm{cm}^{-2}$ ). It means that the stopping of the nitrogen ions in tantalum is mostly due to the electron ion interaction. Therefore, during ion implantation, nitrogen loss from the previously-formed nitride is expected. The nitrogen loss may be responsible for the well-defined composition 
Table 3. Identification of XRD peaks in sample $2\left(\right.$ dose $3 \times 10^{17}$ ions $\left.^{-2}{ }^{-2}\right)$.

\begin{tabular}{lcccccc}
\hline Peak & $2 \theta$ (degree) & $d$ (observed) & $d$ (standard) & $h k l$ & Intensity $(\%)$ & Phase \\
\hline $\mathrm{I}$ & 16.10 & 5.540 & 5.545 & 002 & 3 & - \\
$\mathrm{G}$ & 24.77 & 3.593 & 3.590 & 110 & 0.4 & $\mathrm{TaN}_{0.43}$ \\
$\mathrm{~K}$ & 38.39 & 2.344 & 2.342 & 210 & 86.16 & $\mathrm{bcc} \mathrm{Ta}$ \\
$\mathrm{L}$ & 44.02 & 2.056 & 2.054 & 043 & 3.8 & $\mathrm{Ta}_{3} \mathrm{~N}_{5}$ \\
$\mathrm{M}$ & 55.52 & 1.655 & 1.653 & 300 & 100 & $\mathrm{bcc} \mathrm{Ta}$ \\
$\mathrm{N}$ & 69.61 & 1.350 & 1.245 & 211 & 54.8 & $\mathrm{bcc} \mathrm{Ta}$ \\
$\mathrm{O}$ & 77.59 & 1.230 & 1.451 & 311 & 1.38 & $\mathrm{TaN}$ \\
$\mathrm{P}$ & 82.34 & 1.170 & 1.170 & 202 & 4.2 & $\mathrm{bcc} \mathrm{Ta}$ \\
\hline
\end{tabular}

Table 4. Identification of XRD peaks in sample $3\left(\right.$ dose $5 \times 10^{17}$ ions cm $^{-2}$ ).

\begin{tabular}{lcccccc}
\hline Peak & $2 \theta$ (degree) & $d$ (observed) & $d$ (standard) & $h k l$ & Intensity $(\%)$ & Phase \\
\hline $\mathrm{Q}$ & 24.66 & 3.606 & 3.606 & 110 & 0.3 & $\mathrm{Ta}_{3} \mathrm{~N}_{5}$ \\
$\mathrm{R}$ & 38.30 & 2.349 & 2.347 & 112 & 23 & $\mathrm{bcc} \mathrm{Ta}$ \\
$\mathrm{S}$ & 43.87 & 2.063 & 2.061 & 202 & 0.7 & $\mathrm{TaN}_{0.43}$ \\
$\mathrm{~T}$ & 55.43 & 1.657 & 1.652 & 200 & 100 & $\mathrm{bcc} \mathrm{Ta}$ \\
$\mathrm{U}$ & 68.47 & 1.352 & 1.352 & 211 & 10.8 & $\mathrm{bcc} \mathrm{Ta}$ \\
$\mathrm{W}$ & 82.33 & 1.170 & 1.170 & 220 & 1.8 & $\mathrm{bcc} \mathrm{Ta}$ \\
\hline
\end{tabular}

(a)

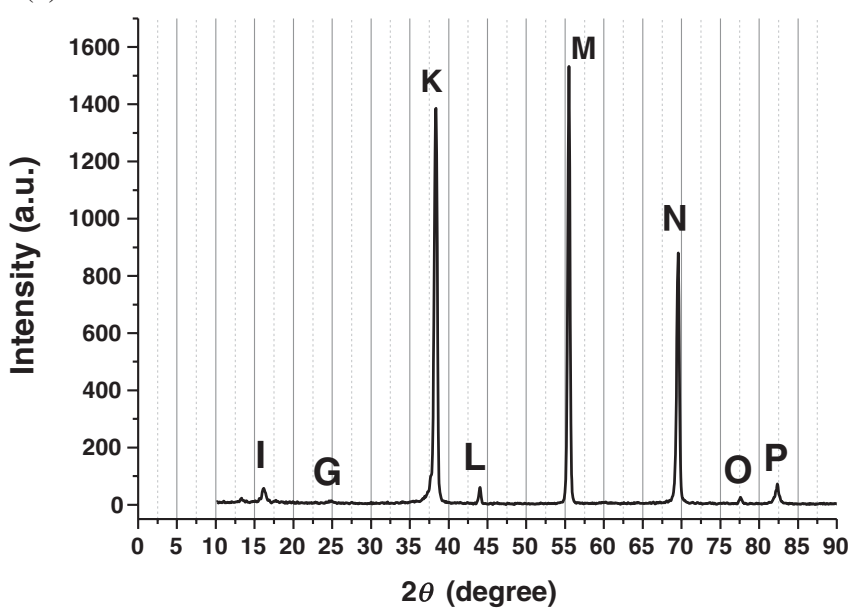

Sample 2

(c)

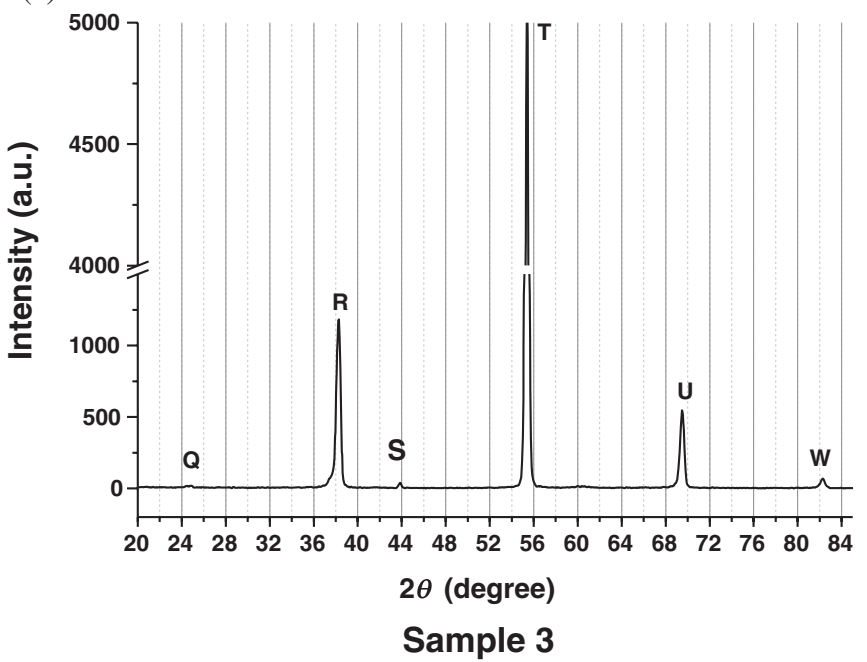

(b)

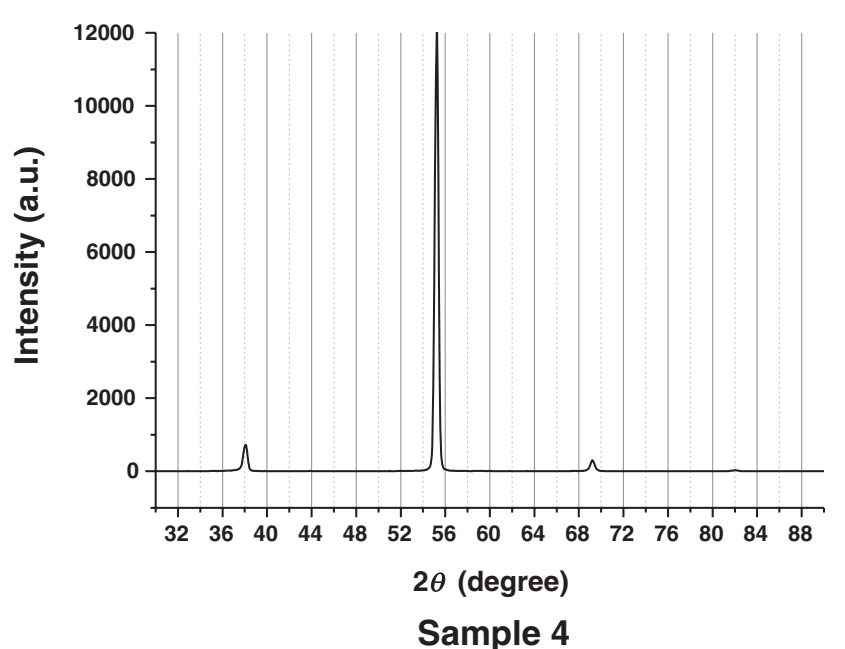

(d)

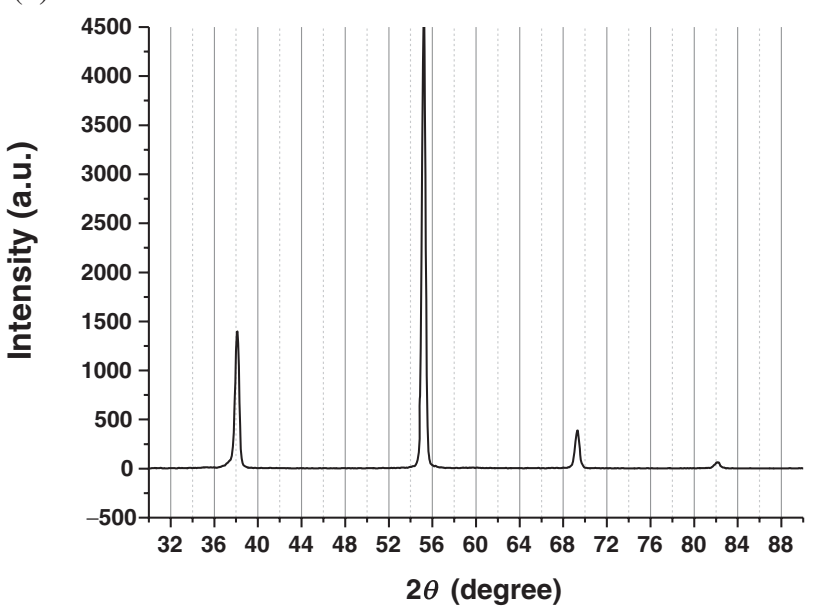

Sample 5

Figure 2. X-ray diffractograms of implanted tantalum with different doses (a) $3 \times 10^{17}$, (b) $5 \times 10^{17}$, (c) $7 \times 10^{17}$ and (d) $10 \times 10^{17}$ ions $\mathrm{cm}^{-2}$. 
change and can form phases with lower stoichiometry. It can be concluded that the peak intensity of samples improves after nitrogen ion implantation and extension of improvement increases with dose. The maximum peak intensity appears at a nitrogen dose of $3 \times 10^{17}$ ions $\mathrm{cm}^{-2}$. At higher dose, the peak intensity decreases (see figure 3 ). This may have been caused by defects due to the excess ion irradiation. The increasing or reducing in the intensity of peaks can be explained, based on the deposition of nitrogen on tantalum substrate and formation of Ta-N. In comparing XRD analyses in all the samples, the presence of Ta-N peaks in the dose of 3 to $5 \times 10^{17}$ ions $\mathrm{cm}^{-2}$ in implanted samples is indicated, which simply results in the formation of crystal structure on the surface of the substrate and the peaks are shifted and decreased at higher doses.

The above results can be understood as follows. Nitrogen is known to occupy interstitial positions in the bec tantalum matrix because of large inter lattice spacings. Thus, for low-dose ion implantations, it is expected that nitrogen will go interstitially. At higher doses, when the depth profile is sputter-limited, nitrogen ions are bombarded on a previously-formed tantalum nitride. The FWHM is related to the defects, grain size and residual strain. XRD pattern reveals the increasing intensity of the (200) direction in implanted samples compared to unplanted sample which also indicate the reduction in the value of full-width at halfmaximum (FWHM). In other words, by increasing ion dose of nitrogen, a reduction is observed in the FWHM of implanted samples which leads to the grain size growth. The apparent grain size can be estimated from the FWHM of the XRD peaks.

Table 5 shows the average grain size (AGS) of the different implanted samples which are obtained from the AFM images, using JMicroVision software. This table clearly indicates that AGS is increased by nitrogen ion implantation process up to the dose of $7 \times 10^{17}$ ions $\mathrm{cm}^{-2}$, which is followed by a reduction at the highest implantation dose (i.e., $1 \times 10^{18}$ ions $\mathrm{cm}^{-2}$ ). This result is in agreement with FWHM of the XRD analysis.

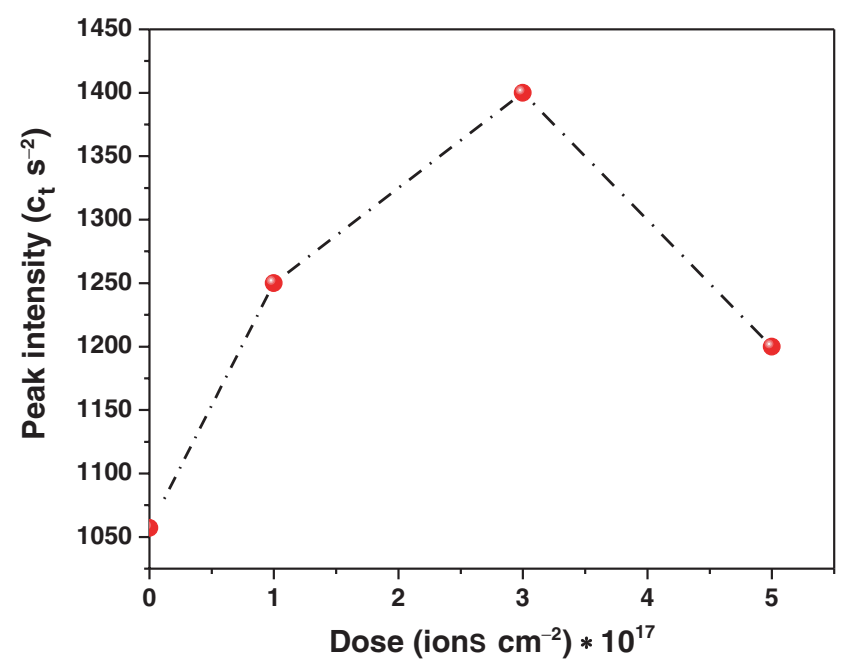

Figure 3. Intensity peak $v s$. different nitrogen ion doses.
For different samples, the intensity of tantalum-nitride peak is decreased and its FWHM is increased with increasing the dose of the nitrogen ions. It can be explained by the fact that for the implanted samples, the high dose of nitrogen ion beam is responsible for causing defects into the surface. In the case of last three samples, this is indicated by the crystallinity of the tantalum nitride films formed at higher doses are poorer by excess $\mathrm{N}$ ions. The crystallite size $D$ (coherently diffracting domains) is obtained using the Scherer formula [34]:

$$
D=\frac{\kappa \lambda}{B \cos \theta},
$$

where $\lambda$ is the wavelength of $\mathrm{X}$-ray, $\theta$ the Bragg angle and $k$ a dimensionless constant which is related to the shape and distribution of crystallites [35] (usually taken as unity). For obtaining the value for $B$, we used the usual procedure of FWHM measurement technique [36], therefore:

$$
B=\left(\omega_{0}^{2}-\omega_{i}^{2}\right),
$$

where $\omega_{0}^{2}$ is the FWHM of the sample and $\omega_{i}^{2}$ the FWHM of stress free sample (annealed powder sample or Si single crystal). The crystallite size D (coherently diffracting domains) variation with increase in dose obtained from XRD peak for Ta are given in table 5. The results shown the increase in crystallite size with increase in dose.

Based on the analysis of the XRD data, the distance between the two planes $(d)$ is calculated using Bragg equation $n \lambda=$ $2 d \sin \theta$ for three different $\theta$ values. Using these $d$ values, the lattices parameter $a$ is calculated by the following relation:

$$
\frac{1}{d^{2}}=\frac{4}{3}\left(\frac{h^{2}+h k+k^{2}}{a^{2}}+\frac{l^{2}}{c^{2}}\right) .
$$

The changes in crystal plane spacing can lead to various lattice constants $a$ due to adjustment of d-spacing, when the lattice constant is increased from $3.310 \AA$ in unimplanted sample to $3.334 \AA$ and $3.252 \AA$ in the implanted samples at doses of $1 \times 10^{17}$ and $5 \times 10^{17}$ ion $\mathrm{cm}^{-2}$, respectively. Finally, the average value of lattice parameter $a$ is determined and the values of lattice parameter $a$ are obtained for different doses.

\subsection{Surface physical morphology}

AFM is a microscope that scans sample surface with a micro tip (cantilever) to enable high-magnification observations of

Table 5. Average grain size, crystal size and FWHM after ion nitrogen implantation.

\begin{tabular}{lccccc}
$\begin{array}{l}\text { Dose } \\
(\text { ions cm }\end{array}$ & & & & & \\
) & $1 \times 10^{17}$ & $3 \times 10^{17}$ & $5 \times 10^{17}$ & $7 \times 10^{17}$ & $10 \times 10^{17}$ \\
\hline $\begin{array}{c}\text { Average grain } \\
\text { size (nm) }\end{array}$ & 51 & 57 & 69 & 106 & 72 \\
$\begin{array}{c}\text { Crystallite } \\
\text { size (nm) }\end{array}$ & 32.3 & 33.1 & 39.7 & 41.0 & 37.3 \\
\hline
\end{tabular}



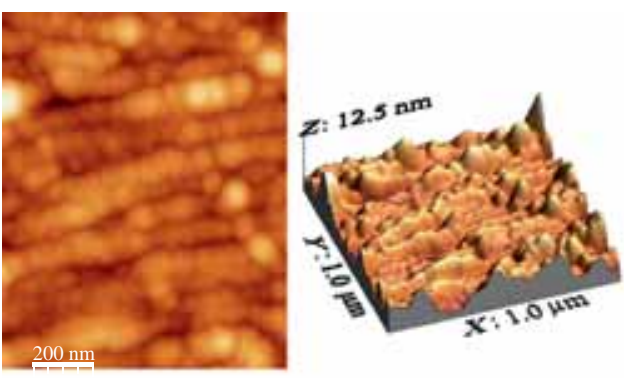

Unimplanted

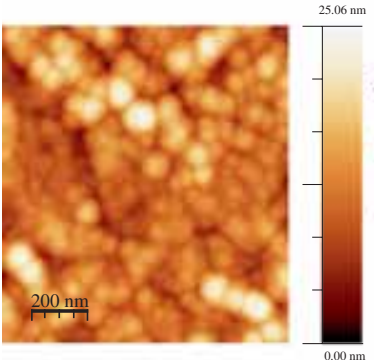

Sample $1\left(1 \times 10^{17}\right.$ ions $\left.\mathrm{cm}^{-2}\right)$
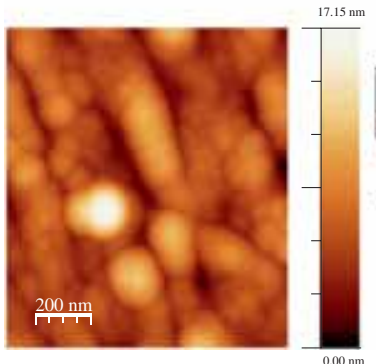

Sample $2\left(3 \times 10^{17}\right.$ ions $\left.\mathrm{cm}^{-2}\right)$
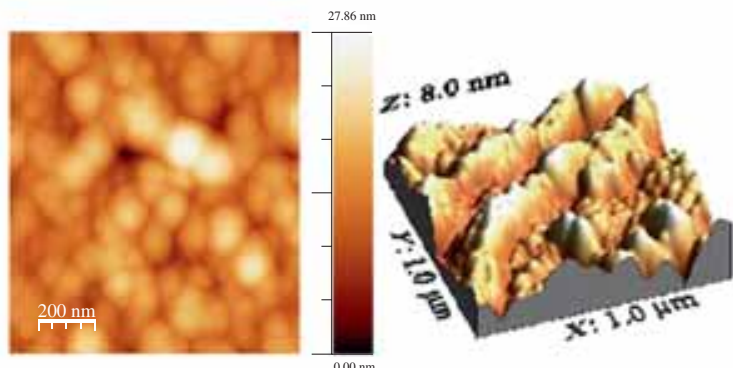

Sample $3\left(5 \times 10^{17}\right.$ ions $\left.\mathrm{cm}^{-2}\right)$
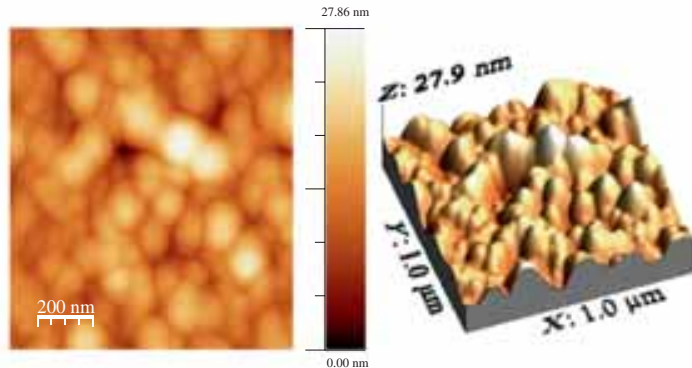

Sample $4\left(7 \times 10^{17}\right.$ ions $\left.\mathrm{cm}^{-2}\right)$
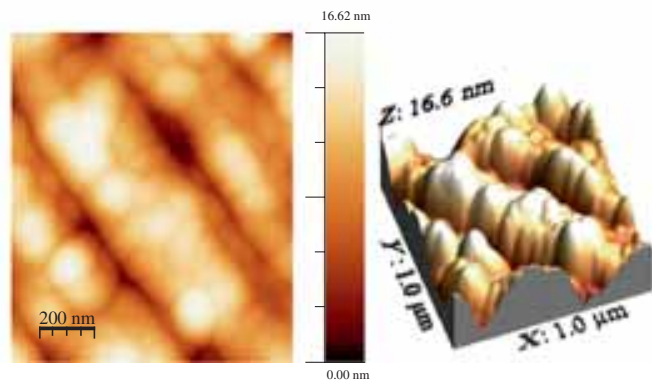

Sample $5\left(10 \times 10^{17}\right.$ ions $\left.\mathrm{cm}^{-2}\right)$

Figure 4. The two- and three-dimensional AFM images of the implanted and unimplanted tantalum with $30 \mathrm{keV}$ nitrogen ions in a different dose $\left(1 \times 10^{17}\right.$ to $10 \times 10^{17}$ ions $\left.\mathrm{cm}^{-2}\right)$.

three-dimensional forms. AFM analysis provided the surface roughness as a function of the lateral length scale and an estimation of the columnar grain size. AFM is also suitable for quantitative study of surface roughness and scaling parameters [36]. By increasing the ion dose, a significant growth in the surface roughness is seen.

Table 5 shows the average grain size of the different implanted samples. This can be identified in the sample as a columnar structure and the grains grew in the form of pyramids with wide peaks which are mostly condensed. For the final dose, this result is in agreement with XRD analysis.

Figure 4 shows the AFM images of a $1000 \times 1000 \mathrm{~nm}$ scan area of the unimplanted sample and implanted with nitrogen ion doses of $1 \times 10^{17}$ to $10 \times 10^{17}$ ions $\mathrm{cm}^{-2}$. There is no significant change in roughness, grain size and distribution for the unimplanted and the lowest implantation dose $\left(1 \times 10^{17}\right.$ ions $\left.\mathrm{cm}^{-2}\right)$. In contrast to this, the average
Table 6. Surface roughness of tantalum and samples implanted with $\mathrm{N}$ ions.

\begin{tabular}{lcccccc}
\hline Sample \# & Unimplanted & 1 & 2 & 3 & 4 & 5 \\
\hline RMS roughness $(\AA)$ & 14.4 & 22.4 & 18.9 & 59.9 & 24 & 40.6 \\
Average roughness $(\AA)$ & 42 & 62.2 & 50.32 & 17.3 & 76.3 & 11.2 \\
\hline
\end{tabular}

grain size (AGS) and roughness are changed for higher doses.

By increase in ion implantation dose, samples' roughness had a significant increase from $5 \times 10^{17}$ up to $1 \times$ $10^{18}$ ions $\mathrm{cm}^{-2}$ (see table 6). Moreover, the surface diffusion mechanism due to ion bombardment could be responsible for the roughness enhancement. However, the decrease in roughness could be caused by higher sputtering rate during ion bombardment. 


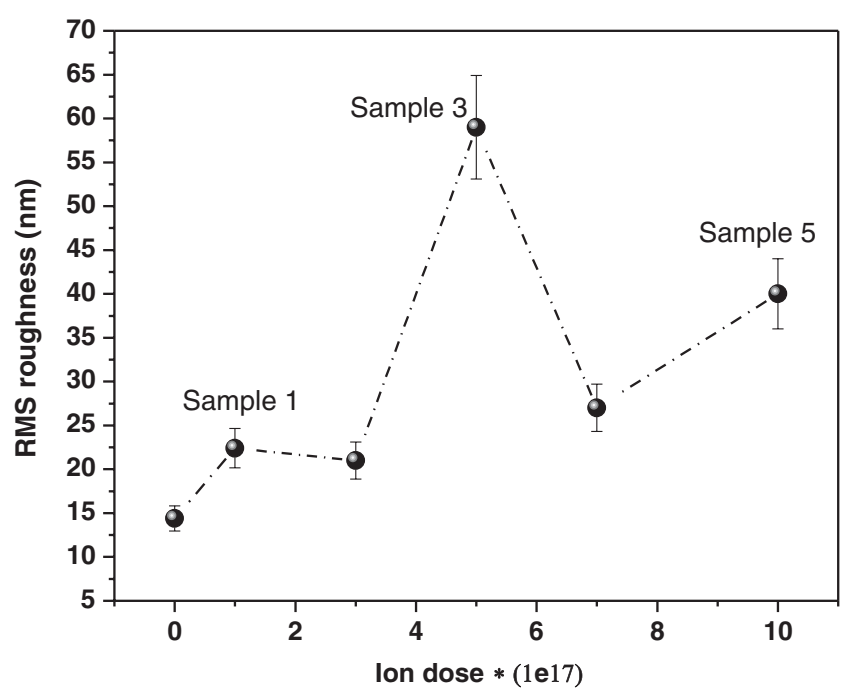

Figure 5. Variation of the RMS roughness as a function of implantation dose.
Figure 5 shows the root mean square (RMS) roughness of unimplanted and some of the implanted samples. The AFM images show that there is an increase in the rms roughness of the samples. Surface roughness increases with the nitrogen ion dose up to $3 \times 10^{17} \mathrm{~cm}^{2}$, after which roughness values decreases with a dose of $7 \times 10^{17}$ ions $\mathrm{cm}^{-2}$. The increase in rms roughness value is due to implantation-induced sputter cones and to disorder in the tantalum surface. The reduction in the roughness at a dose of $7 \times 10^{17}$ ions $\mathrm{cm}^{-2}$ might be due to deformation on the surface.

As previously confirmed by XRD analysis, the crystallite size gradually increases with increasing nitrogen ion dose. The reason can be related to the fact that the ion dose enhancement promotes the mobility of ad atoms and results in the increase of grain size. By further increase in the ion dose, the ion density becomes large enough for crystal growth; thus, the grain size increases slightly with an increasing dose. The surface diffusion mechanism due to higher

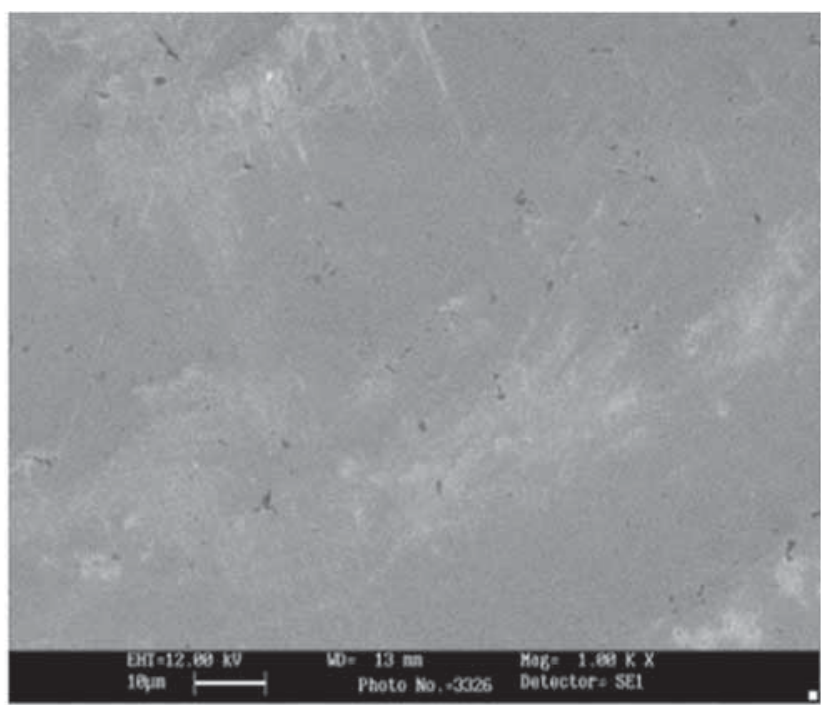

(c)

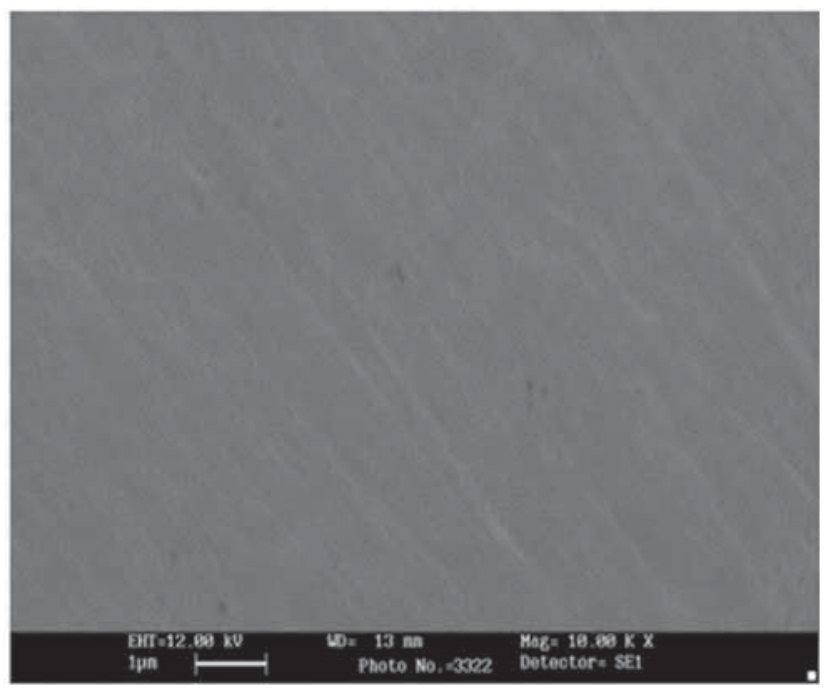

(d) (b)

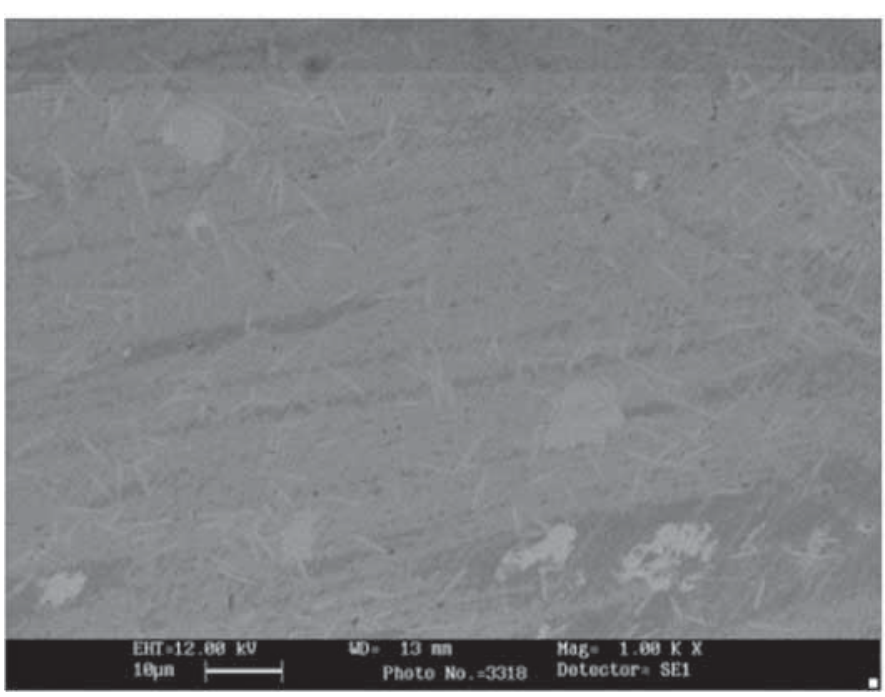

Figure 6. SEM images micrograph of nitrogen implanted for (a) unimplanted, (b) $3 \times 10^{17}$, (c) $5 \times 10^{17}$ and (d) $10 \times 10^{17}$ ions $\mathrm{cm}^{-2} \mathrm{doses}_{\text {. }}$ 
number of ions in the implantation process is responsible for this change.

\subsection{Scanning electron microscope}

Surface morphology of the ion implantation was observed using a field emission SEM. SEM micrographs are shown in figure 6. It can be clearly seen that when the implantation dose increases, the surface morphology and texture can change dramatically. The SEM study of the surface structure of unimplanted sample has shown that the surface structures are smooth. Some defects that were observed on the surface of the samples (figure 6a) are related to some mechanical micro-damages produced during sample preparation. Figure $6 \mathrm{~b}$ is the SEM image of implanted sample with a dose of $3 \times 10^{17}$ ions $\mathrm{cm}^{-2}$. At a larger magnification; the granular structure characteristic was observed with the average dimension of clusters of about $57 \mathrm{~nm}$.

SEM investigations of the implanted sample have shown (figure $6 \mathrm{~b}, \mathrm{c}$ ) that the surface structure is changed after the ion implantation. For higher implantation dose of $5 \times 10^{17}$ ions $\mathrm{cm}^{-2}$ is shown in figure $6 \mathrm{c}$, the surface is modified and granular structure is less pronounced. This can be the onset point for nitrogen saturation on the surface and modification caused by the energetic incoming ions. Further implantation of nitrogen ions onto the surface $\left(10 \times 10^{17}\right.$ ions cm$\left.^{-2}\right)$ is shown in figure 6d. The SEM image shows a smoother surface with no blister-like texture. This is in agreement with AFM result where a smaller grain size and average roughness are observed.

\section{Conclusion}

We can see from the above analysis that there is a structural correlation between different tantalum nitrides. The results demonstrate that direct ion implantation is a powerful technique to form metal nitrides in the near-surface region. XRD analysis confirms the successful formation of tantalum nitride phase which is promoted by increasing ion implantation dose. Also, AFM results show that the implanted sample at the dose of $5 \times 10^{17}$ ions $\mathrm{cm}^{-2}$ has and almost uniform surface with homogenous distribution particles. Nitrogen ion implantations of the samples with different fluxes lead to change in the structure crystallographic. The shift and broadening of the peak are associated with, and produced by nitrogen super saturation and associated stress caused by the nitrogen remaining in solid solution in the lattice. For ionimplanted sample at $1 \times 10^{17}$ ions $\mathrm{cm}^{-2}$ new phases are not observed. At a higher dose of 3 to $5 \times 10^{17}$ ions $\mathrm{cm}^{-2}$, many additional peaks are observed which are due to fcc $\mathrm{TaN}_{0.43}$, tantalum phases, respectively. In various samples, the intensity of tantalum-nitride peak is increased and its FWHM is increased by increasing the dose of the nitrogen ions. Other factors such as the thermodynamic factor, temperature and sputtering should also be taken into consideration. The exact mechanism of phase transformation in ion implantation needs to be further investigated.

\section{Acknowledgements}

We extend special thanks to Dr A H Sari for the helping discussion and A Shokouhy for the implantation processes. This work was supported by Plasma Physics Research Center, Science and Research Branch of Islamic Azad University.

\section{References}

[1] Budzyński P, Tarkowski P, Jartych E and Kobzev A P 2001 Vacuum 63737

[2] Liu Y, Zu X, Qiu S and Huang X 2006 Rare Metals 25309

[3] Shikha D, Jha U, Sinha S K, Barhai P K, Nair K G M, Dash S et al 2009 Surf. Coat. Technol. 2032541

[4] Black J 1994 Clinic. Mater. 16167

[5] Matsuno H, Yokoyama A, Watari F, Uo M and Kawasaki T 2001 Biomaterials 221253

[6] Chen G S and Chen S T 2000 J. Appl. Phys. 878473

[7] Chang C-C, Jeng J S and Chen J S 2002 Thin Solid Films 413 46

[8] Arranz A and Palacio C 2000 Surf. Interf. Anal. 29653

[9] Takano I, Isobe S, Sasaki T A and Baba Y 1989 Appl. Surf. Sci. 3725

[10] Ignatenko P I, Klyakhina N A and Badekin M Y 2005 Inorg. Mater. 4136

[11] Zhou X, Dong H K, Li H D and Liu B X 1989 Vacuum 39 307

[12] Zhang Q Y, Chen B, Li G B, Jin S, Chen F X, Yang D Z et al 1994 Surf. Coat. Technol. 66468

[13] Wang W J, Wang T M and Wang 1996 Nucl. Instrum. Meth. Phys. Res. Sect. B $\mathbf{1 0 8} 300$

[14] Arranz A and Palacio C 2005 Appl. Phys. A 811405

[15] Raole P M, Narsale A M, Kothari D C, Pawar P S, Gogawale S V, Guzman L et al 1989 Mater. Sci. Eng. A 11573

[16] Mehrotra B and Stimelli J 1987 Vac. Sci. Technol. B 51736

[17] Ezugwu E O and Wallbank J 1987 Mater. Sci. Technol. 3 881

[18] Terao N 1971 Jpn. J. Appl. Phys. 10248

[19] Willmott D J 1972 J. Appl. Phys. 434865

[20] Wilson I H 1976 Thin Solid Films 33205

[21] Belii I M, Komarov F F, Tishkov V S and Yankovskii V M 1978 Phys. Status Solidi A 45343

[22] Petrovic R 1979 Thin Solid Films 57333

[23] Aita C R and Mayers T A 1983 J. Vac. Sci. Technol. A I 348

[24] Kolonits V P and Czermann M 1985 Thin Solid Films 12345

[25] Holloway K, Fryer Peter M, Cabral Cyril Jr, Harper J M E, Bailey P J and Kelleher K H 1992 J. Appl. Phys. 71 5433

[26] Min K H, Chun K C and Kim K B 1996 J. Vac. Sci. Technol. B 143263

[27] Kaloyeros A E and Eisenbraun E 2000 Annu. Rev. Mater. Sci. 30363 
[28] Riekkinen T, Molariusa J, Laurilab T, Nurmelaa A, Sunia I and Kivilahtib J K 2002 Microelectron. Eng. 64289

[29] Leng Y X, Sun H, Yang P, Chen J Y, Wang J, Wan G J et al 2001 Thin Solid Films 398471

[30] Saha R and Barnard J A 1998 J. Cryst. Growth 174495

[31] Willmott D J 1972 J. Appl. Phys. 434865

[32] Wilson I H 1976 Thin Solid Films 33205
[33] Aita C R and Mayers T A 1983 J. Vac. Sci. Technol. A I 348

[34] Klung H and Alexander L 1954 X-ray diffraction procedure (New York: Wiley) p 503

[35] Krim J and Palasantazas G 1995 Int. J. Mod. Phys. B9 599

[36] Kelly R 1982 Radiat. Effects 64205 